


\title{
CARACTERÍSTCAS DO MOVIMENTO DE MASSA GRAVITACIONAL NA REGIÃO DA PRAINHA, ÁREA URBANA DO MUNICÍPIO DO RIO DE JANEIRO (BRASIL)
}

\author{
CHARACTERIZATION OF GRAVITATIONAL LANDSLIDE \\ IN THE REGION OF PRAINHA, URBAN AREA \\ OF RIO DE JANEIRO CITY (BRAZIL)
}

R. Porto Jr. ${ }^{1}$, G. R. Gouveia ${ }^{2}$, B. P. Pires ${ }^{3}$, V. S. Brandão ${ }^{4} \&$ N. M. Coutinho ${ }^{5}$

Resumo - Em Maio de 2010, após intensas chuvas que perduraram por cerca de 24 horas, registrou-se um movimento de massa gravitacional de grandes proporçôes na região oeste da cidade do Rio de Janeiro na zona litorânea da regiáo denominada de Prainha. Este trabalho apresenta as características geológico-geotécnicas deste acidente. O trabalho de campo realizado apontou para a existência de padróes estruturais, geomorfológicos e de variaçóes litológicas que favoreceram a detonação e a amplitude do movimento. Dentre destes aspectos, podemos realçar a presença de juntas de alívio, fraturas de espaçamento considerável e forte processo de intemperismo químico, que, em conjunto, atuaram no enfraquecimento do maciço rochoso favorecendo o estabelecimento do acidente. Os resultados aqui apresentados foram obtidos através de um estudo sistemático que envolveu etapas de campo, análise estrutural, análise petrográfica (macro e microscópica) e testes em laboratório.

Palavras-chave - Movimento de massa; Geologia de engenharia, Geologia estrutural; Deslizamento de solo

\footnotetext{
${ }^{1}$ Dep. de Geociências, UFRuralRJ, BR-465, KM 7, Seropédica, 23890-000; rubempjr@gmail.com

2 Dep. de Geociências, UFRuralRJ, BR-465, KM 7, Seropédica, 23890-000; gabriellargouveia@gmail.com

${ }^{3}$ Dep. de Geociências, UFRuralRJ, BR-465, KM 7, Seropédica, 23890-000; brunopgeo@yahoo. com.br

${ }^{4}$ Dep. de Geociências, UFRuralRJ, BR-465, KM 7, Seropédica, 23890-000; vitorgeologia@yahoo. com.br

${ }^{5}$ GeoRio-SMO, Campo de São Cristóvão, 268, Rio de Janeiro, 20.921-440; nelsonmeirim@ hotmail.com
} 
Abstract -A geological and geotechnical characterization of a large landslide in Prainha region, located in the west part of the city of Rio de Janeiro, was carried out. The landslide occurred in May 2010, after 24 hours of intense rainfall. Structural, geomorphologic and lithologic conditions favorable to landslide were identified, such as release joints, wide spaced fractures and strong chemical weathering processes. The results and conclusions were obtained based on field work, structural and petrographic (macro and microscopic) analyses, and laboratory tests.

Keywords - Mass movement, Engineering geology, Structural geology, Soil
landslide

\section{1 - Introduçáo}

A regiâo litorânea correspondente às praias de Grumari e Prainha, entre os dias 5 e 6 de Abril de 2010, foi palco de um grande movimento de massa gravitacional. Verificou-se a queda de um bloco de cerca de $1000 \mathrm{~m}^{3}$ que provocou um movimento de massa estimado em pelo menos $12.000 \mathrm{~m}^{3}$ de material, constituindo este o maior movimento de massa local registrado nos últimos 25 anos na cidade. Devido a ter ocorrido numa área não habitada, as suas maiores consequências foram a interdiçáo de uma estrada litorânea e a modificação do perfil da praia local. A geologia dessa regiâo está caracterizada a partir de trabalhos de detalhe (mapeamentos geológicos em escala 1:10.000) realizados desde os anos 1990 (CORREA e PORTO Jr., 1999). Do ponto de vista geotécnico, a estrada que atravessa a região apresenta várias intervençóes, muitas realizadas ainda durante a abertura da estrada na década de 1970. O local do movimento de massa corresponde a uma APA (Área de Proteçáo Ambiental) municipal.

\section{2 - Objetivo e metodologia}

O objetivo da pesquisa realizada foi caracterizar e avaliar os aspectos geológicos e geotécnicos envolvidos na situação de instabilidade, já que a geologia da região, pelas suas características, certamente contribuiu para a amplificação da instabilidade. Para o desenvolvimento da pesquisa, foi realizado trabalho de campo, onde amostras foram coletadas para a realização de análises petrográficas (macro e microscópicas) e de resistência. Realizou-se ainda a coleta de dados estruturais (foliaçóes, lineaçōes e fraturas) na área afetada e de seu entorno. A área estudada está localizada na zona oeste da cidade do Rio de Janeiro, nos contrafortes do Maciço da Pedra Branca (Fig. 1). A situação de instabilidade ocorreu na Avenida Estado da Guanabara nos limites do Parque Ecológico da Prainha, uma Área de Proteção Ambiental Permanente (APA). A ocorrência da isntabilidade interrompeu a principal ligaçâo entre os bairros limítrofes e a região de Grumari por um largo tempo, obrigando aos frequentadores a utilizar um caminho alternativo que aumentava o percurso em cerca de $20 \mathrm{~km}$. $\mathrm{O}$ acesso à área instabilizada é feito a partir da Estrada do Pontal (Praia da Macumba) ou pela Estrada de Grumari a partir de Guaratiba. 


\section{3 - Características geomorfológicas da área afetada}

No período de verão (dezembro a março), o fluxo de veículos na estrada afetada pelo movimento de massa é intenso devido à beleza cénica do local e à qualidade das praias da região. Quando de sua construção, boa parte da estrada foi implantada através de cortes e aterros no sopé da encosta do Morro Boa Vista, contornando a escarpa rochosa que se projeta diretamente sobre o mar. Especificamente na área afetada pelo movimento de massa, a presença de um conjunto de intervençôes de engenharia, é indicativa da existência, desde a época da abertura da estrada, de problemas geotécnicos. A declividade média do terreno onde a estrada foi implantada é acentuada. As cotas mais elevadas são superiores a $300 \mathrm{~m}$, alcançando valores acima de $400 \mathrm{~m}$ na confluência dos morros Boa Vista, Caeté e das Piabas (Fig. 2). Uma linha de cumeada - no sentido leste-oeste - divide a área em duas bacias de captação de águas pluviais. Ao sul, onde as águas são direcionadas para o oceano, ocorre um divisor convexo - de sentido norte-sul - que forma a linha de cumeada do Morro Boa Vista, separando os anfiteatros das bacias de drenagem da Praia de Grumari, a oeste, e da Prainha, a leste.

\section{4 - Características geológicas da área afetada}

As rochas da região estão divididas em dois conjuntos distintos: ortognaisses encaixantes que se enquadram nos litotipos da Série Inferior (HELMBOLD et al., 1965) e por granitóides de composiçôes e estruturas variadas (CORREA e PORTO Jr, 1999, PORTO Jr., 2004). Do ponto de vista estrutural as rochas encaixantes mostram direçôes preferenciais com caimento para SE / $\left(155^{\circ} / 25^{\circ}\right)$. Esta direção preferencial pode estar flexionada para SW/S $\left(220^{\circ} / 20^{\circ}\right)$. Os ortognaisses apresentam composição variável (diorítica a granodiorítica), e estão deformados e migmatizados (Fig. 3). As rochas de composição diorítica são rochas ricas em plagioclásio, biotita, hornblenda e quartzo, apresentando titanita. São rochas bandadas com texturas lepidoblásticas, deformadas e com foliação bem definida. As rochas ortoderivadas de composição granodiorítica apresentam ortoclásio, plagioclásio, quartzo e biotita. São rochas granoblásticas com bandamento metamórfico pouco desenvolvido. A descrição detalhada de cada um dos litotipos gnáissicos foi apresentada por PORTO Jr. et al. 1991. As rochas graníticas presentes correspondem a fácies do Granito Pedra Branca (PORTO Jr e VALENTE, 1988). Ocorrem formando corpos tabulares em contatos intrusivos com as rochas encaixantes gnáissicas ortoderivadas (Fig. 4), correspondem a rochas leucocráticas, de textura inequigranular que, na fácies predominante na área, apresenta textura levemente foliada, sendo que esta foliação está associada a fluxo magmático e não a processos tectônicos, sendo portanto, diferente das foliaçôes encontradas na rocha gnáissica. A sua composição mineralógica revela a presença de microclina, plagioclásio, quartzo e muito pouca biotita. 


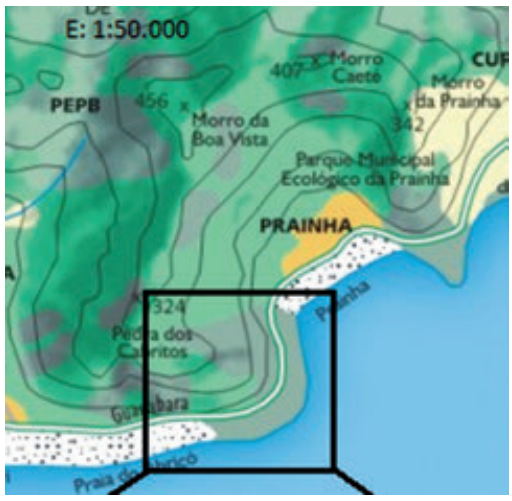

Fig. 1 - Localização da Área afetada pelo escorregamento.

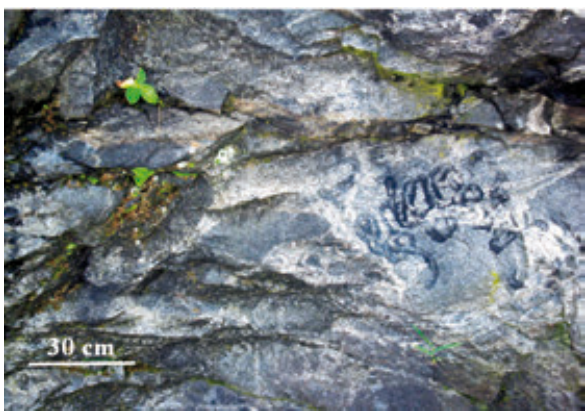

Fig. 3 - Gnaisse de composição diorítica a granodiorítica.

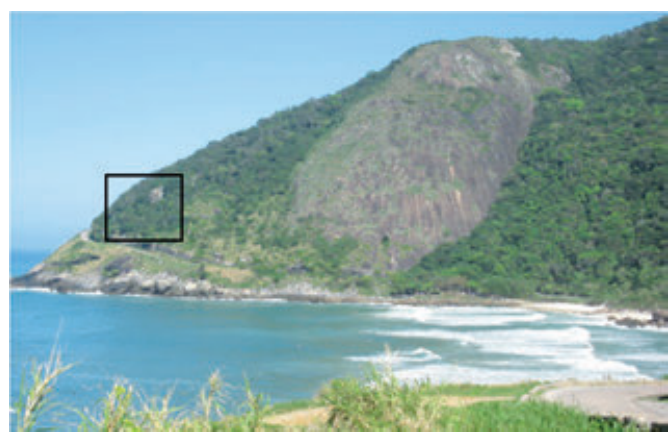

Fig. 2 - Características topográficas do terreno. Linha cumeada e quebra do perfil. morfológico.

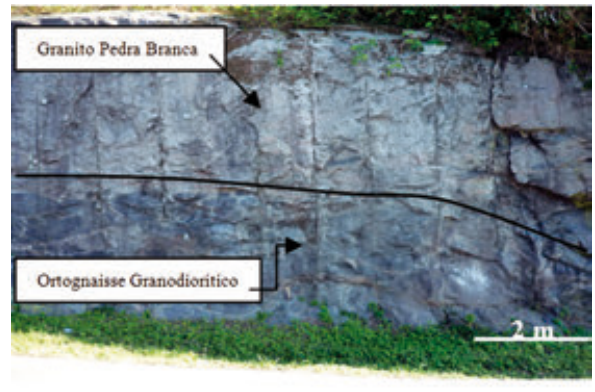

Fig. 4 - Corpos tabulares em contatos intrusivos com as encaixantes gnáissica.

\section{5 - O movimento de massa gravitacnal da Prainha: caracterização}

Como consequência da intensa precipitação ocorrida na noite de 5 e madrugada de 6/4/2010, com um valor acumulado de $232,6 \mathrm{~mm}$ entre as $17: 30 \mathrm{~h}$ do dia 5 e as $17: 30 \mathrm{~h}$ do dia 6 , e um pico de 33,6 mm numa hora, às 17:40h do dia 5 de acordo com os dados da estação pluviométrica da Grota Funda, Sistema Alerta-Rio, ocorreu um movimento de massa de grandes proporçóes, que mobilizou aproximadamente $12.000 \mathrm{~m}^{3}$ de blocos de rocha e material terroso (Fig. 5). Parte da massa escorregada ultrapassou os limites da Av. Estado da Guanabara alcançando as águas do mar com o restante do material se espalhando numa área de aproximadamente $12.000 \mathrm{~m}^{2}$. Apesar da magnitude da situação de instabilidade, não houve vítimas nem danos materiais além da destruição da estrada no trecho atingido e de parte das obras de contenção previamente existentes (Fig. 6). Registre-se ainda que basicamente a quase totalidade do material movimentado corresponde a material granítico, já que os gnaisses se encontram ao nível dos cortes da estrada e sustentados por obras de contenção. 
A partir dos levantamentos (geológico, geológico-estrutural, geotécnico) efetuados no local do acidente, logo após sua ocorrência, foi possível reconstituir a cronologia do evento:

1) o movimento teve início a partir do deslocamento de um gigantesco bloco de rocha granítica (cerca de $3.000 \mathrm{~m}^{3}$ ), que na queda se fragmentou em seis outros blocos de grandes dimensôes;

2) este deslocamento ocorreu devido ao grande volume de águas pluviais registrado na tarde do 5 de abril e na madrugada do dia 6 de abril, que, levando à saturação do solo, provocou o aumento do impulso na camada do material terroso acumulado na fenda existente por trás do bloco;

3) a decomposição química na área de apoio do bloco movimentado, e a ação da força da gravidade, em consequência do deslocamento do centro de gravidade desse bloco, foram fatores importantes e decisivos na deflagração do movimento;

4) ao tombar, o bloco principal impeliu outro bloco de rocha, com cerca de $800 \mathrm{~m}^{3}$ de material também granítico, de forma arredondada, que se encontrava isolado na sua frente, projetando-o para o mar (Figs. 7 e 8);

5) esse processo iniciou um escorregamento que mobilizou enormes massas de material quase que totalmente de composição granítica e um considerável volume de solo, avaliado entre 10.000 a $12.000 \mathrm{~m}^{3}$;

6) toda a área passa por um forte processo de intemperismo químico, em associação com a fragmentaçáo de parte considerável do material existente a meia encosta;

7) a investigação realizada comprovou que todo o movimento de massa se deu no domínio de ocorrência do Granito Pedra Branca. A totalidade dos blocos analisados é da rocha granítica;

8) ficou evidente, ainda, a existência de depósitos de blocos localizados a meia encosta, possivelmente associados a um movimento de massa anterior;

9) deve destacar-se a existência de um padrão estrutural bem definido, associado às fraturas presentes na rocha e inerentes aos litotipos encontrados facilitadora para a formação de blocos de tamanhos variados, mas com tendência a gerar blocos retangulares e/ou arredondados, que ocorrem na encosta (Fig. 9);

10) juntas de alívio e fraturas com espaçamento de até $10 \mathrm{~cm}$ (média de $4 \mathrm{~cm}$ ) em associação às feiçóes geradas pela foliação de fluxo, devem ser motivo de investigação mais detalhada e devem, necessariamente, ser consideradas quando da opção de solução de obra estabilizante para áreas com estas características.

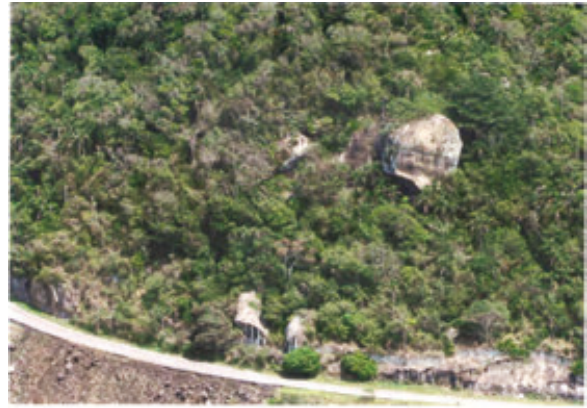

Fig. 5 - Vista da área antes do escorregamento.

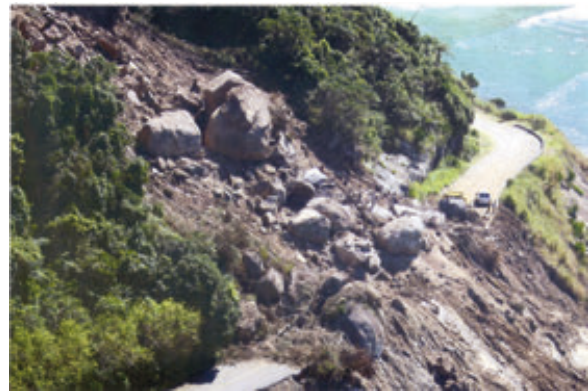

Fig. 6 - Vista da área após o escorregamento. 


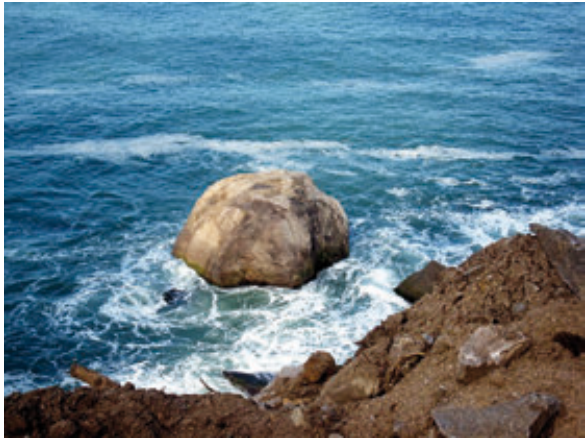

Fig. 7 - Bloco de granito lançado ao mar.

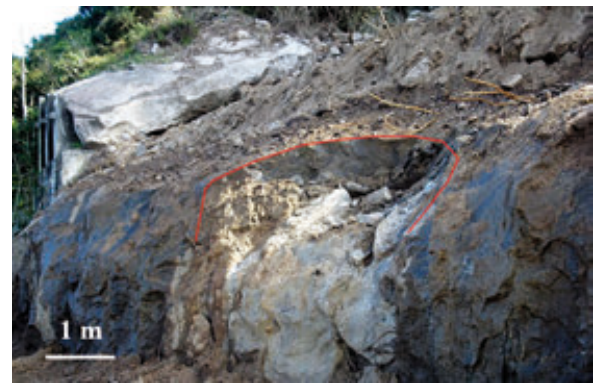

Fig. 8 - Estrutura de impacto ocasionada pelo bloco lançado ao mar.

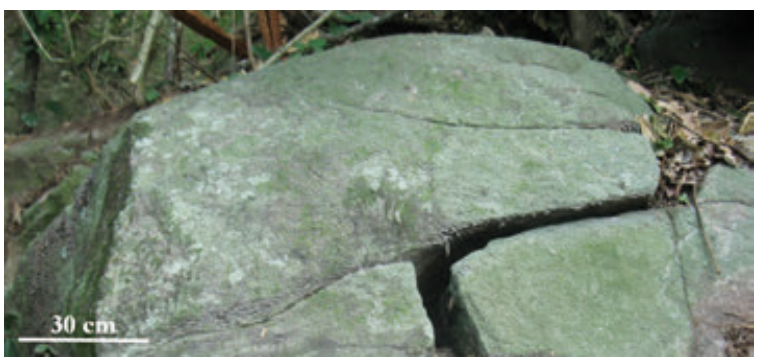

Fig. 9 - Bloco apresentando o padráo ortogonal das estruturas.

\section{6 - Condicionantes da situação de instabilidade}

São aqui consideradas como condicionantes geológicas todos os fatores ligados a aspectos geológico/geomorfológicos observados na área que tenham tido influência direta ou indireta no desencadeamento do movimento de massa gravitacional como: 1) intervençóes de engenharia pretéritas; 2) a alta declividade do terreno, que favorece a mobilização do material à meia encosta; 3) famílias ("Set") de fraturas com direçóes ortogonais (N30E; N70E e N30W) que dão origem aos blocos cúbicos/quadrados e que são posteriormente arredondados pelo efeito do intemperismo. Isso ocorre porque a litologia dominante, caracterizada por uma composição granítica é uma rocha que apresenta relativa isotropia. Este fator condiciona uma alteraçáo com desgaste relativo similar em todas as suas direçôes, gerando um padrão de arredondamento subordinado a estrutura da rocha; 4) alteração química, representada principalmente por sericitização e saussuritização; 5) presença de juntas de alívio e foliação esferoidal; 6) presença de intemperismo químico e físico, nos litotipos identificados, evidenciado pela oxidação dos minerais ricos em ferro (biotita). Por se tratar de um íon de raio de pequena dimensão, este é assimilado no início da cristalização destes minerais e quando expostos a condiçóes muito diferentes daquelas de sua formação em conjunto com ambientes propícios à hidratação, apresentam tendência para sofrerem lixiviação química. 


\section{7 - Ensaio em laboratório}

Amostras de composição granítica coletadas na etapa de campo foram submetidas a ensaio para determinação de sua resistência. Esta etapa foi realizada no LAMAGE (Laboratório de Mapeamento Geológico) da UFRuralRJ (Universidade Federal Rural do Rio de Janeiro). O ensaio constou da utilização do martelo de Schmidt (Tipo L) ou esclerômetro de recuo para obtenção dos resultados referentes a sua resistência. Para realização do ensaio processou-se as amostras de forma que através de corte laminar obteve-se duas faces planares, uma para apoio e fixaçáo da amostra, e outra para receber o choque com o esclerômetro. As amostras ensaiadas foram separadas em três tipos, de acordo com a alteração observada: rocha sâa, onde os cristais euédricos de microclina estavam preservados e a biotita não se mostrava alterada; rocha medianamente alterada, onde os grãos de microclina apresentavam menor brilho do que os da rocha sã e, a vista desarmada, era possível observar a alteração nos grãos de plagioclásio e biotita; e rocha muito alterada, onde observou-se a presença de alteração intempérica, evidenciada pela presença de capa ferruginosa nos limites da amostra. Neste caso, a rocha apresentava menor coesão, com grãos bem mais alterados o que caracterizava maior fragilidade na porção amostrada. Foi possível ainda, nestas amostras, observar uma mudança na coloração dos grãos de microclina, que passaram a ter tons mais cinza/amarelados (Fig. 10).

Com a individualização das amostras nestes três segmentos, o ensaio foi realizado com um intervalo de 5 a 15 impactos por amostra, sendo assim possível a determinação da dureza superficial e consequentemente a resistência à compressão da rocha. O resultado representa a média dos resultados obtidos para cada conjunto de amostras. O ensaio realizado nos forneceu o valor da Dureza de Schmidt. Os valores obtidos estão apresentados na Tabela 1. A partir desses valores e da massa específica da rocha (no caso do litotipo estudado foi atribuído o valor de $2,7 \mathrm{~g} / \mathrm{cm}^{3}$ obtido em AMARAL (1997) para este mesmo tipo de rocha), foi possível estimar a resistência à compressão em MPa relativa a cada uma das amostras analisadas através das correlaçóes de DEERE e MILLER (1966) (Fig. 11).

Verificou-se uma diminuição dos valores de resistência à compressão uniaxial com o incremento do grau de alteração. Logo, temos que a rocha sã é, como esperado, a mais resistente, enquanto a rocha muito alterada é a de menor resistência, o que está de acordo com comportamento previsto em SCHWENCK et al. (2010). Assim, pode ser caracterizado que a situação de instabilidade estava associada à diminuição dos valores de resistência do maciço rochoso já que durante a realização dos trabalhos de campo observou-se que o material alterado correspondia, a maior parte do volume movimentado $(\approx 60 \%)$ enquanto o material medianamente alterado e o material náo alterado correspondiam a valores subordinados $(\approx 25$ e $15 \%$ respectivamente). 


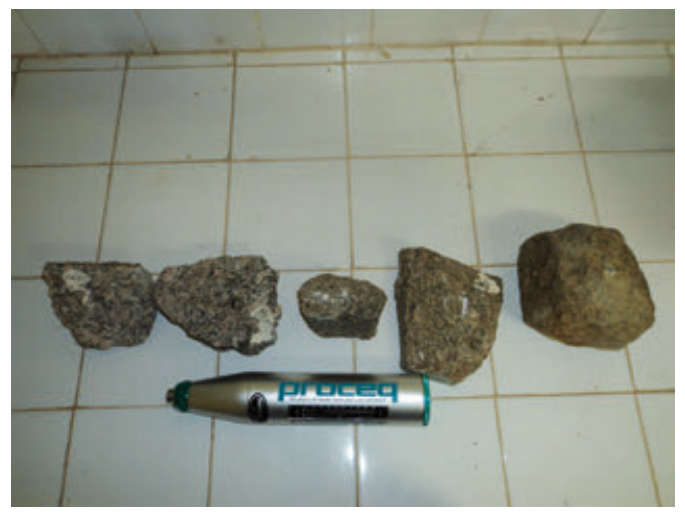

Fig. 10: Esclerômetro e amostras ensaiadas.

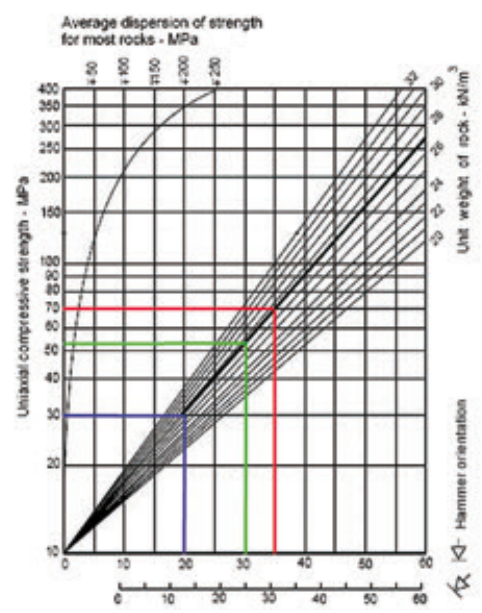

Tabela 1

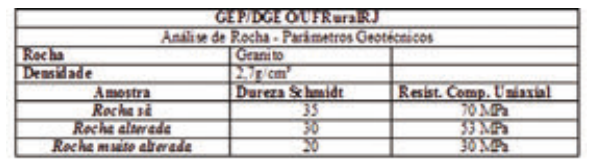

Fig. 11 - Resultado do ensaio de compressão uniaxial, tabela de Schmidt.

\section{8 - Recuperação da área}

Durante todo o período de desmonte e recuperação da área afetada pelo movimento de massa, que durou oito meses, a Av. Estado da Guanabara foi mantida fechada por questôes de segurança. O retorno à sua utilização somente se deu quando do término da realização da contenção da área com a construção de cortinas atirantadas e muros de novos contenção, e recuperação da estrada (Fig. 12). Como parte da recuperação da área e da solução de obra teve de ser levado em conta o fato de que o movimento de massa deixou dois grandes blocos, localizados na parte alta do local afetado pelo movimento de massa, muito instáveis e apresentando forte descalçamento em suas bases. Estes blocos, com volume de até $2.000 \mathrm{~m}^{3}$ cada um, foram entấo desmontados a fogo e o material 
lançado na parte da encosta que termina no mar dando mais segurança ao local. Como náo havia local nas proximidades que pudesse servir para o recolhimento do material movimentado pelo escorregamento, optou-se por deslocar em direção ao mar um grande volume de material. Recomendou-se que deveria ser estabelecido um procedimento de constante avaliação com relação a eventuais impactos que este material lançado ao mar possa a vir provocar na sedimentação da Prainha mudando sua forma (perfil de praia) bem como a qualidade de suas ondas (Fig.13), já que trata-se de um local de forte apelo pela beleza da paisagem e pela qualidade das ondas, sendo um dos principais pontos da prática do surfe na área da cidade. Outro fator de relevância é que foram detectados, pelos estudos de campo realizados na região, situaçóes geológico / geomorfológicas similares às que originaram o movimento de massa que foi descrito e estudado no presente trabalho. Recomenda-se, portanto, a manutençáo de uma contínua observação da área do entorno do acidente, para que nela seja realizada uma contínua avaliação que permita a realização de intervençóes que minimizem novas situaçôes de instabilidade.

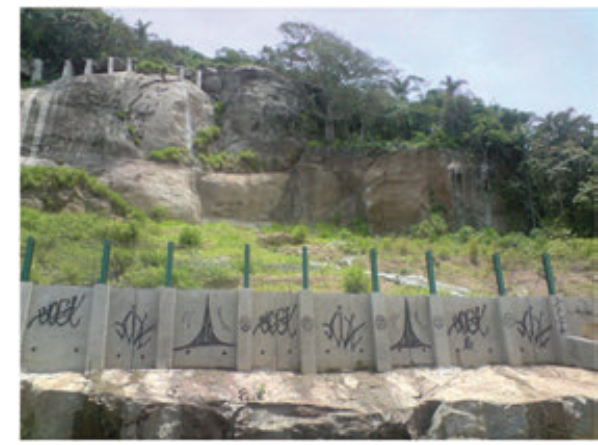

Figura 12 - Obra finalizada.

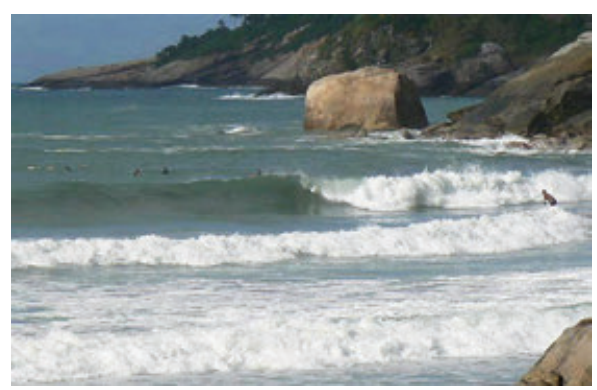

Figura 13 - Bloco rolado que pode modificar a morfologia da praia.

\section{9 - Conclusôes}

Com base no apresentado, podemos concluir que a situação de instabilidade da encosta na região da Prainha-Grumari está associada a presença de material rochoso intemperizado fisica e quimicamente e relacionado a rocha de composição granítica. O início do movimento se associa a ocorrência de fortes e concentradas chuvas, fato que permitiu a rápida e intensa lixiviação do material alterado que sustentava os grandes blocos presentes. Estes blocos, localizados a meia encosta, têm sua formaçáo subordinada a presença de uma família de fraturas que, combinadas, facilitaram a formação de blocos retangulares a arredondados de volumes variados que se mantêm em frágil equilíbrio no local. Com base nos dados obtidos, observou-se que a maior parte dos blocos movimentados apresentavam-se fortemente intemperizados e com baixa resistência. Observou-se ainda que o deslizamento ocorreu exclusivamnte na área de predomínio de rocha granítica e que, portanto, as contençóes pretéritas presentes na área foram capazes de sustentar as rochas gnáissicas presentes na base do talude e que, efetivamente, não contribuíram para este acidente. A realização das obras dá segurança ao local, entretanto, a não retirada 
de parte dos depósitos ainda presentes nas partes laterais da encosta deve ser motivo de preocupação e de monitoramento permanente.

\section{Referências Bibliográficas}

AMARAL, C. (1997) - Escorregamentos no Rio de Janeiro: Inventário, Condicionantes geológicas e Redução de Risco. Tese de Doutoramento. DEC-PUC-RJ. 286p.

CORREA, R.P. \& PORTO JR., R. (1999) - Modelamento geoquímico aplicado às rochas da região Prainha-Grumari, complexo granítico Pedra Branca (CGPB), Rio de Janeiro, RJ. In: Anais V Congresso de Geoquímica dos Países de Língua Portuguesa, Ed. SBGq, p. 476-478.

DEERE, D.U. \& MILLER, R.P. (1966) - Engineering classification and index properties for intact rock. Report AFWL-TR - 65 - 116. Air Force Weapons Laboratory (WLDC), Kirtland Air Force base, New Mexico.

HELMBOLD, R., VALENÇA, J.G. \& LEONARDOS JR., O.H. (1965) - Mapa geológico do Estado da Guanabara, esc. 1: 50000. 3 Folhas. MME/DNPM.

PORTO JR, R. (2004) - Petrogênese das Rochas do Complexo Granítico Pedra Branca, Rio de Janeiro, RJ. IG-UFRJ, 224p.

PORTO JR, R. \& VALENTE, S.C. (1988) - As rochas granitóides do norte da Serra da Pedra Branca e suas relaçốes com as encaixantes gnáissicas na região de Bangu, Rio de Janeiro, RJ. In: Anais do 35 Congresso Brasileiro de Geologia, Belém, 3, p. 1066-1079.PORTO JR, R.. VALENTE, S.C e DUARTE, B.P. (1991) Geologia do Pontal de Barra de Guaratiba: implicaçóes petrogenéticas relacionadas ao Batólito da Serra da Pedra Branca, Rio de Janeiro, RJ. In: Anais do 2o Simpósio de Geologia do Sudeste. São Paulo, SP.

PORTO JR., R., VALENTE, S. C. \& DUARTE, B. P. (1991) - Caracterização do Magmatismo Brasiliano no Paleozóico Inferior: o exemplo do plúton Pedra Branca, Rio de Janeiro, RJ, Brasil.. In: I Conferência Internacional Sobre el Paleozóico Inferior de Ibero-América., 1991, Mérida, Espanha.. Anais da I Conferência Internacional Sobre el Paleozóico Inferior de Ibero-América, v. 1. p. 103-105.

SCHWENCK, V., PIRES, B. P., GOUVEIA, G. R. \& PORTO JR, R. (2010) - Movimento de Massa na Região da Prainha-Grumari, Município do Rio de Janeiro: Caracterização Geológico-Geotécnica. In: XX Jornada de Iniciação Científica da UFRRJ. Seropédica, RJ. 